\title{
The Determination of the Static Anthropometric Characteristics for the Computer Users from the Monitoring Room of one of the Industries in the Mazandaran Province for Designing an Ergonomic Chair
}

\author{
Mohammad Amin Mououdi ${ }^{1 *}$, Seyyed Mohsen Hosseini
}

1. Faculty member, School of Public Health, Mazandaran University of Medical Sciences, Sari, Iran

2. B.Sc. in Industrial Engineering, North University, Amol, Iran

\begin{abstract}
Article Info
Original Article

Received: 25 Sep 2017;

Accepted: 14 Jan. 2018;

Published Online 2018/01/23

DOI: $10.30699 /$ jergon.5.3.22

Use your device to scan and read the article online

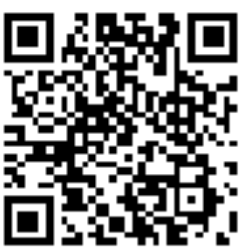

Corresponding Author Mohammad Amin Mououdi Faculty member, School of Public Health, Mazandaran University of Medical

Sciences, Sari, Iran

Tel: 09113111931 Email:

Mououdi2006@yahoo.com

\section{ABSTRACT}

Background: Sitting for long periods of time is a part of the illness, which can happen in the workplace and the lack of attention to the ergonomic principles causes musculoskeletal disorders such as backache, pelvic ache, shoulder ache, elbow ache, arm ache, wrist and ankle ache, and muscle aches in the other parts of the body. The present research was carried out according to the ergonomic principles and designs, in order to design an ergonomic chair, suitable for the computer users in the monitoring room of one of the industries in the Mazandaran province.

Methods: The participants in this study included a total of 32 male staff from the monitoring room of one of the industries in the Mazandaran province. A total of 24 anthropometric parameters were measured from the body of each of the subjects, sitting in a vertical position on an adjustable chair, using anthropometric calipers and meters and the data were analyzed with the Excel and the Minitab statistical programs.

Results: The mean age of the subjects was $42.59 \pm 5.34$ years and the $5^{\text {th }}, 25^{\text {th }}$, $50^{\text {th }}, 75^{\text {th }}, 90^{\text {th }}$, and $95^{\text {th }}$ percentiles of their anthropometric dimensions and Pearson's correlation coefficients were obtained to design the height, the depth, the height, and the width of the ergonomic chair. All parts of the chair had two degrees of freedom. The neck and back supports, adjustable for this type of chair were designed specifically. Also, using MIT standards, the level of seat compressibility was measured to be $4.26 \mathrm{~cm}$, based on the $95^{\text {th }}$ percentile weight.

Conclusion: Considering that other countries design and produce suitable chairs, focusing on the anthropometric characteristics of the individuals, studies, similar to this research could be recommended in the different parts of the country, in order to design and produce appropriate chairs for the physical dimensions of the people and their needs.
\end{abstract}

Keywords: Anthropometry; Ergonomic chair; Design; Workplace

Copyright $(\odot$ 2018, Journal of Ergonomics. This is an open-access article distributed under the terms of the Creative Commons Attribution-noncommercial 4.0 International License which permits copy and redistribute the material just in noncommercial usages, provided the original work is properly cited.

\section{How to Cite This Article:}

Mououdi M A, Hosseini M. The Determination of the Static Anthropometric Characteristics for the Computer Users from the Monitoring Room of one of the Industries in the Mazandaran Province for Designing an Ergonomic Chair. J Ergon. 2018; 5 (3) :22-28 


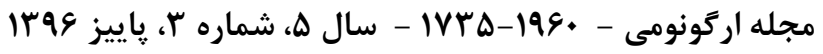

\section{مقاله يثزوهشى}

تعيين مشخصههاى آنترويومترى استاتيكى كاربران رايانة اتاق مونيتورينَ يكى از صنايع استان مازندران براى طراحى صندلى اركونومى ايستغاه كار

محمدامين موعودى "، سيد محسن حسينى r

1. عضو هيئتعلمى، دانشكدة بهداشت، دانشكاه علوم بزشكى مازندران، سارى، ايران ז. آ. كارشناس مهندسى صنايع، دانشكاه شمال، آمل، ايران

\begin{tabular}{|c|c|}
\hline خلاصه & اطلاعات \\
\hline 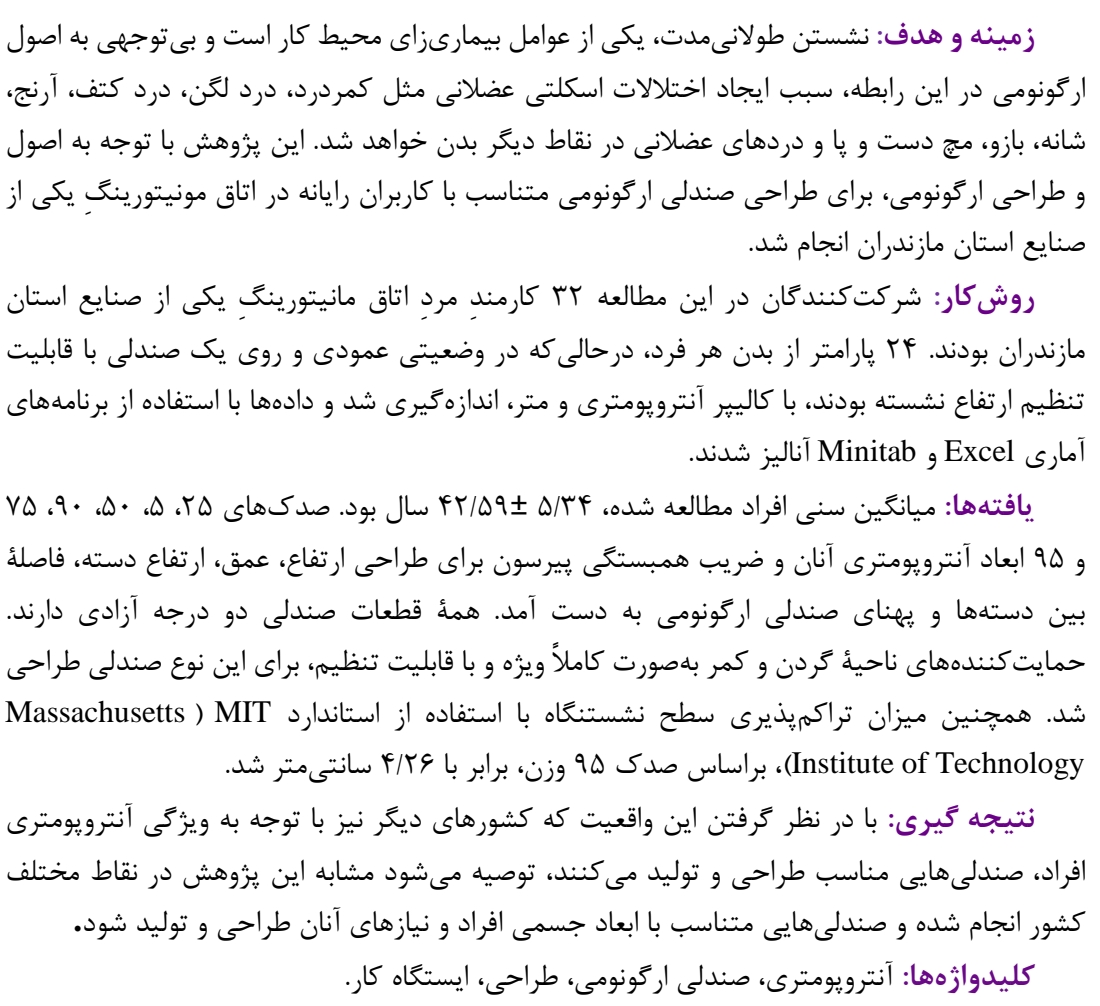 & 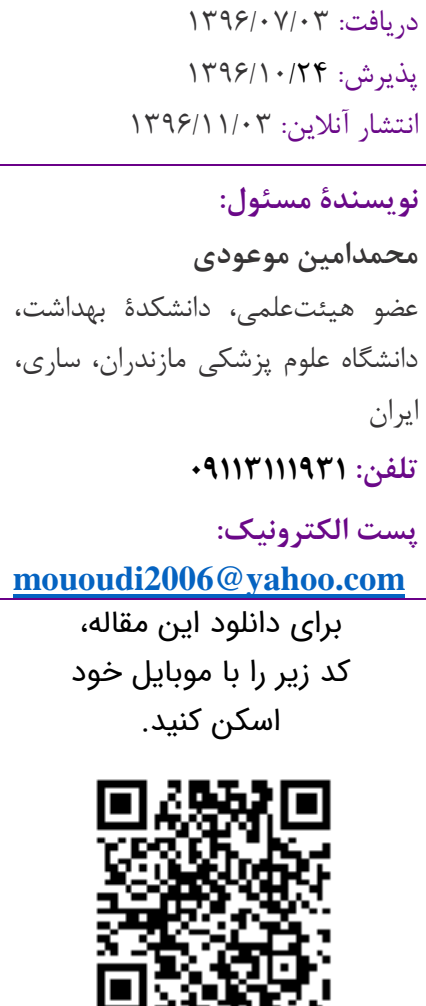 \\
\hline
\end{tabular}

مقدمه

دست و پِا و دردهاى عضلانى در ديخر نقاط بدن خواهد

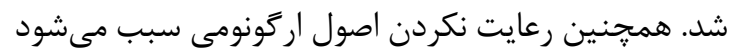
كه كارگر در محيط كار خيلى زود خسته شود و بدين ردين ترتيب ميزان كارايى و بهرهورى او كاهش يابد. نيز احتمال

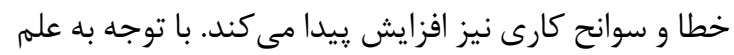

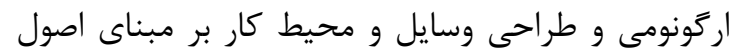

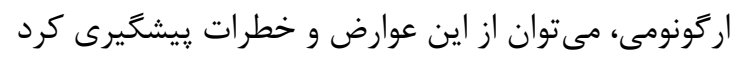
[r. $\left[r^{2}\right]$
در بسيارى از محيطهاى كارى، طراحى ايستخاه كارى

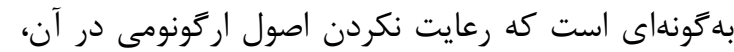
فرد را در معرض عوامل زيانآور قرار مى اسدهد. نشستن طولانىمدت يكى از اين عوامل بيمارىزاى محيط كار

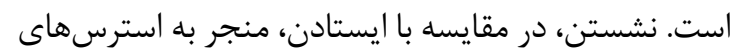
زيادترى مىشود و بىتوجهى به اصول ارگونومى نشستن

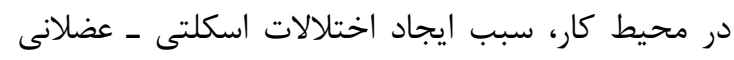
مثل كمردرد، درد لخن، درد كتف، آرنج، شانه، بازو، مج مجيج 
براى جلوگيرى از بالا رفتن دماى كوره و مخزن و به تبع آن

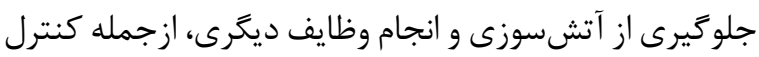

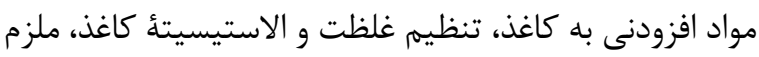
به نشستن روى صندلى هستند. كل كاربران مانيتورينغ اين

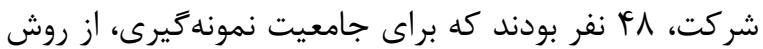

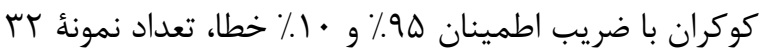

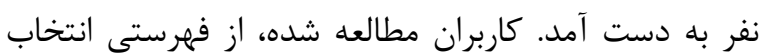
شدند كه از واحد HSE شركت كرفته شد.

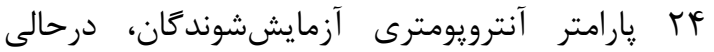

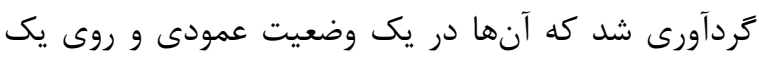
صندلى با قابليت تنظيم ارتفاع با سطحى افقى نشسته بودند

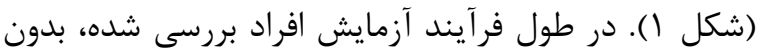

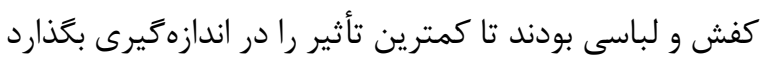

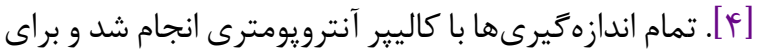
بعضى قسمتها، از متر فلزى و متر منعطف و عمقسنج با باديا دقت در حد دهم ميلىمتر استفاده شد. تمام دادههاى

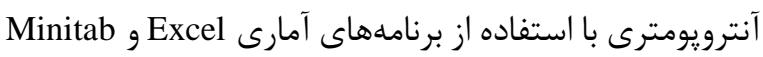

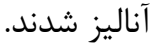

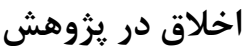

كليه افراد با آكاهى، رضايت و داوطي داوطلبانه در اين يزوهش

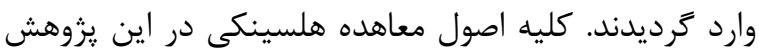
رعايت كرديد.

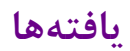

افراد شركتكننده در اين يزوهش ميانكين سنى I آ

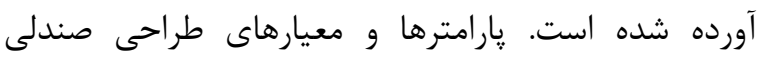

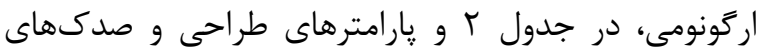

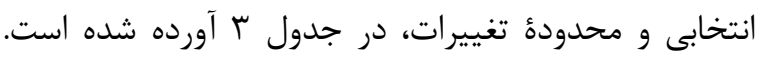

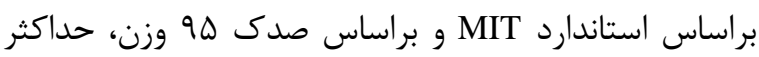

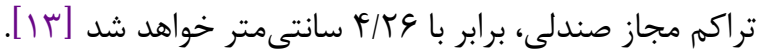

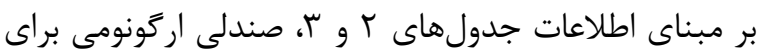
كاربران واحد مانيتورينگ واحد صنعتى مذكور طراطنى ساخته شد (شكلهاى ك و ؟َ).
در ارتباط با نشستن طولانىمدت و عوارض ناشى از آن، توليدكنندكان صندلى به طراحى قشتىهايى انديشيدهاند كه

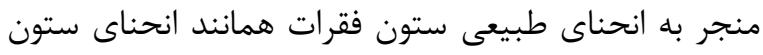
فقرات يوسجر ايستاده شود. بيشتر اندازمخيرىهاى انجامشده

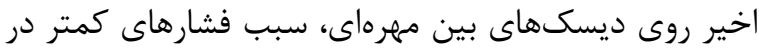

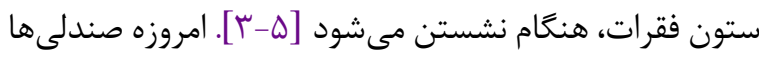
به صورتى طراحى مىشوند كه در همأ جهات حركت كنند و قادر به ايجاد تطابق در وضعيتهاى مختلف باشند. به اين لحاظ، به اينگونه صندلىها، صندلىهاى ديناميك گفتها

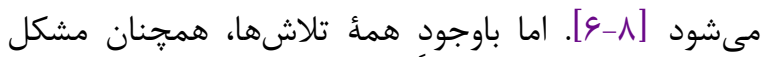

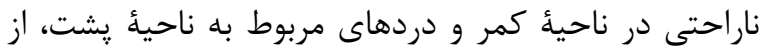

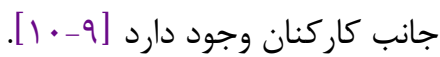
مقصود از ساخت صندلى، فراهن

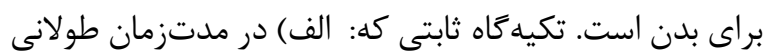
راحت باشد. ب) ازنظر روانى رضايتبخش باشد. ج) براى

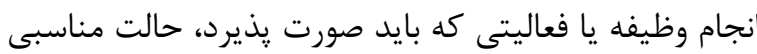

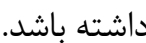
به دليل نبودِ صندلىهاى طراحىشده براساس اصول اركونومى در بسيارى از صنايع، از جمله در صنعت بررسى شده

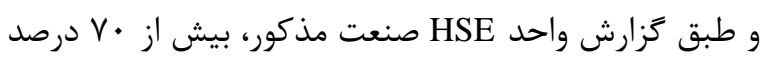
كاركنان شاغل در اين واحد براساس برسشنامة ،Cornell Musculoskeletal Discomfort Questionnaires) مشكلات اسكلتى ـ عضلانى داشتند؛ بنابراين براى پيشگَيرى از مشكلات اسكلتى - عضلانى، كاهش كار ايى و خستكى در افراد شاغل در اين صنعت، اين مطالعه در واحد مذكور انجام شد و درنهايت كونهاى صندلى ديناميك طراحى شد شد كه در

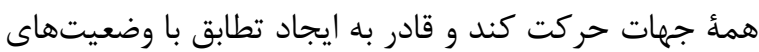

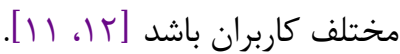

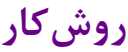

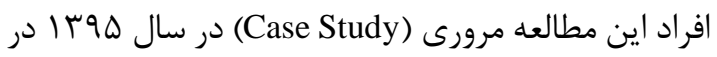

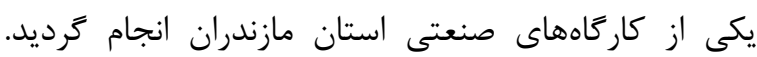
شركت كنندكان در اين مطالعه، همكى مرد و كاربران رايانه اتاق مونيتورينگ يكى از كاركاههاى صنعتى استان مازندران

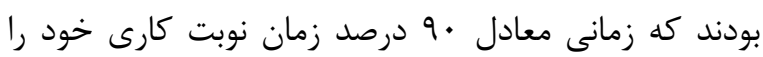


جدول (. ابعاد آنترويومترى شركتكنندًَان (اعداد برحسب سانتىمتر)

\begin{tabular}{|c|c|c|c|c|c|c|c|c|}
\hline $\mathrm{SD}$ & صدى ه9 & Vدى VD & صدى • ص & صدى ه & صدك ه & علامت & نام پارامتر & No \\
\hline$\Delta / T^{\mu}$ & $\Delta I / T \Lambda$ & FE/TT & $F Y / D Q$ & एN/9G & TI/NI & & سن & 1 \\
\hline$N / T F$ & $q F / T F$ & $\Lambda \varepsilon / T q$ & $1 \cdot 199$ & $V \Delta / \cdot \Lambda$ & SV/IT & & وزن & $r$ \\
\hline$\Delta / \Delta \Delta$ & $|\Lambda| / 94$ & $\mid V \varepsilon / Y \wedge$ & $|V Y / D|$ & IEN/VF & גא/זו & & قد & $r$ \\
\hline$T / \cdot \Delta$ & FF/G9 & $F T / G \Lambda$ & $f 1 / r q$ & ५q/q. & $r V / 9 T$ & $\mathrm{a}$ & ارتفاع ركبى & f \\
\hline$T / 1 Q$ & $\Delta V / T^{\complement}$ & س & $\Delta r / \Lambda V$ & $\Delta Y / F)$ & 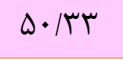 & b & ارتفاع زانو (نشسته) & $\Delta$ \\
\hline$r / 19$ & $9 \Delta / r V$ & $q Y / T q$ & $9 \cdot 11 r$ & $\wedge V / 9 \Delta$ & $\Lambda F / \Lambda V$ & $\mathrm{c}$ & ارتفاع نشسته & $q$ \\
\hline$r / 1 Q$ & \&ヘ/Vq & $9 \Delta / V \Delta$ & $94 / 9 \mid$ & $q 1 / 4 V$ & $\Delta \Lambda / F F$ & d & ارتفاع شانه & v \\
\hline T/9T & $r r / \Delta G$ & $r q / V q$ & TV/VG & $r \Delta / V V$ & rT/QG & e & صندلى ارتفاع تكيه حاه آرنج تا كف & $\Lambda$ \\
\hline$V / \Delta)$ & VA/AV & VI/GT & 99101 & $91 / 4$. & $\Delta F / \| Q$ & $\mathrm{f}$ & زارتفاع آرنج نشسته تا كف & 9 \\
\hline$T / I T$ & GI/Ar & $\Delta 9 / \vee q$ & $\Delta \wedge / \Gamma \Delta$ & $\Delta \varphi / 91$ & $\Delta F / \Lambda V$ & g & طول باسن - زانو (نشسته) & 1. \\
\hline $1 / \Delta \Lambda$ & $r q / \uparrow \wedge$ & rV/ą & rG/A & $r \omega / \Lambda \cdot$ & TH/TV & $\mathrm{h}$ & طول شانه - آرنج (نشسته) & 11 \\
\hline$T / \Delta F$ & $\Delta 1 / T 1$ & FN/AS & FV/T & $F \Delta / F$. & GT/qF & $\mathrm{i}$ & طول باسن ركبى & ir \\
\hline $1 / \Delta T$ & rq/10 & rF/G & ه/ & rr/gl & rI/lf & $\mathrm{j}$ & طول ساعد & Ir \\
\hline שץ/r & $\Delta \Delta / 9 T$ & $\Delta T / \Lambda$. & $0 \cdot 19$. & $\boldsymbol{F} / \boldsymbol{F}^{\mathrm{c}}$. & FT/TA & $\mathrm{m}$ & يهناى عرضى آرنج تا آرنج & if \\
\hline $1 / 90$ & $f / / \Lambda$ & $f \cdot / \cdot 1$ & 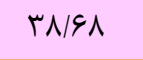 & ( & $r \Delta / ז \wedge$ & $\mathrm{n}$ & يهناى باسن (نشسته) & 10 \\
\hline$T / T G$ & $\Delta 1 / \cdot F$ & FN/AS & EV/TT & $F \Delta / v \wedge$ & Fr/g. & 1 & 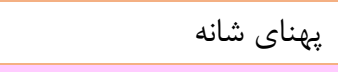 & 19 \\
\hline $1 / \pi 9$ & $1 \cdot 1 \Lambda$. & 1.119 & १/Vद & س/T & N/VI & o & ي يهناى ساعد & IV \\
\hline 1/א & $19 / V T$ & $|N / F|$ & $1 V / 4 q$ & $19 / 09$ & $\mid \omega / T \Delta$ & $\mathrm{k}$ & ضخامت ران & 11 \\
\hline T/YF & וא/זr & $T / / D$ & $19 / 94$ & $|N / 1|$ & $10 / 90$ & $\mathrm{~s}$ & ارتفاع عمودى گودى كمر & 19 \\
\hline$T / T \Delta$ & TH/Tr & $T T / \cdot G$ & $r \cdot / F V$ & IN/AV & $19 / 9$. & $\mathrm{t}$ & طول كَودى كمر & $r$. \\
\hline זr/. & $T / I T$ & $1 / \wedge 1$ & $1 / 09$ & $1 / r V$ & $1 / \cdot \Delta$ & $\mathrm{u}$ & عمق گودى كمر & rI \\
\hline$T / F F$ & $r V / \cdot q$ & TF/VF & $r \mu / \cdot \Lambda$ & TI/ET & $19 / \cdot 9$ & $\mathrm{p}$ & ارتفاع عمودى گودى گردن & rt \\
\hline$r|9|$ & 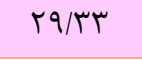 & r\&|A & $r \Delta / \cdot r$ & & $r \cdot / V q$ & q & طول گَودى كردن & 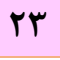 \\
\hline.$/ 91$ & $\varepsilon / F V$ & ه/D & F/A & $F / T$. & T/TG & $\mathrm{r}$ & عمق گودى گردن & rF \\
\hline
\end{tabular}

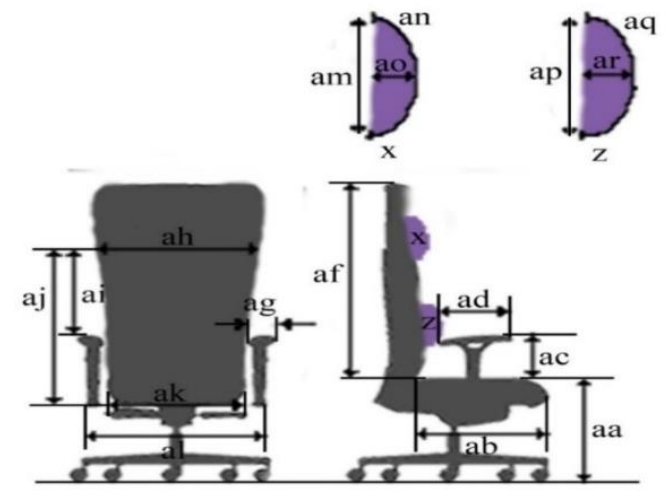

شكل r. اجزاء طراحى صندلى ارَّونومى

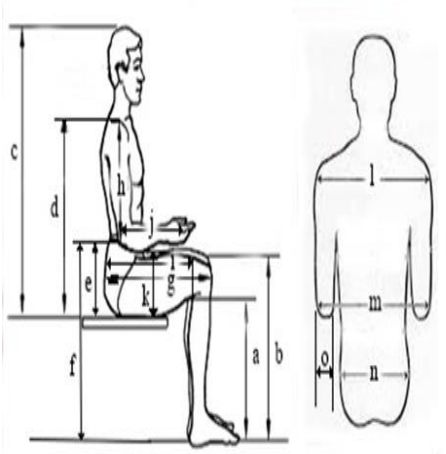

شكل ا. ابعاد آنترويومترى شركت كنندگًان 


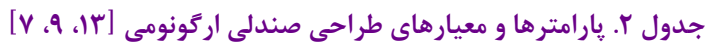

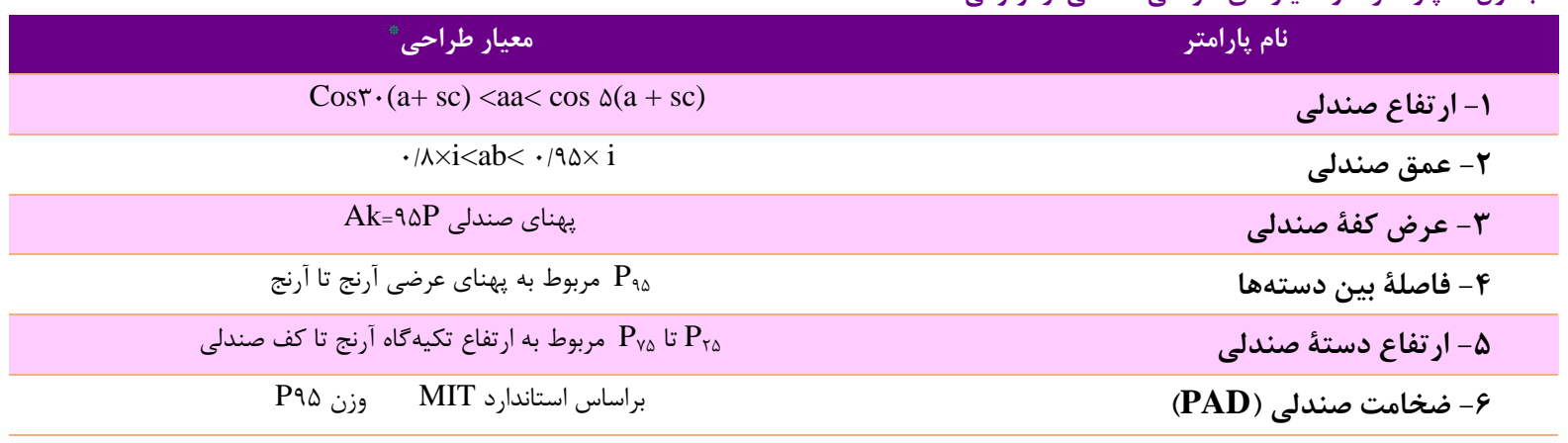

جدول r. ارارامترهاى طراحى و صدك هاى انتخابى و محدودة تغييرات

\begin{tabular}{|c|c|c|c|c|c|}
\hline محدودة تغييرات & سانتى متر & استفادهده صدى & إِارامتر آنترويومترى درهد طراحى & قسمت عنوان & ن ام قسمت \\
\hline$r / \Psi \cdot<x<r \Delta$ & re/qT & $\Delta$ & ارتفاع ركبى & aa & ارتفاع صندلى \\
\hline$V q / \mathcal{F} \cdot\langle x<r q / r r$ & FT/qF & $\Delta$ & طول باسنر كبى & $\mathrm{ab}$ & عمق صندلى \\
\hline$\Lambda / T q<x<r \Delta / r$ & $r V / \Delta V$ & $\Delta \cdot$ & صندلى ارتفاع تكيه كاه آرنج تا كف & $\mathrm{ac}$ & ارتفاع دستهُ صندلى \\
\hline- & re/10 & $9 \Delta$ & طول ساعد & $\mathrm{ad}$ & طول دستهُ صندلى \\
\hline- & $9 \Delta / T^{\prime}$ & $9 \Delta$ & 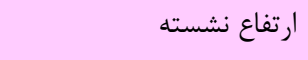 & af & ار تفاع يشتى صندلى \\
\hline- & $1 \cdot 1 / 99$ & 90 & يهناى ساعد & ag & ضخامت دستة صندلى \\
\hline- & $\Delta 1 / \cdot r$ & 90 & 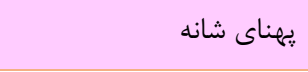 & ah & عرض يشتى در قسمت شانه \\
\hline- & FI/A & 90 & 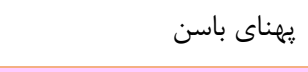 & ak & عرض يشتى در قسمت باسن \\
\hline- & $r q / \uparrow \wedge$ & 90 & طول شانه آرنج & ai & ارتفاع دسته تا عرض در قسمت شانه \\
\hline- & GN/VA & 90 & ارتفاع شانه & aj & ارتفاع كفه تا عرض در قسمت شانه \\
\hline- & $F I / A \Lambda$ & 90 & يهناى باسن & ak & عرض كفهُ صندلى \\
\hline$\Delta \Delta / q T<X<F \Delta / r q$ & $\Delta \Delta / 9)$ & 90 & يهناى عرضى آرنج تا آرنج & al & فاصله بين دستهها \\
\hline كل رشتى & $19 / .9$ & $\Delta$ & ارتفاع عمودى گودى گردن & am & ارتفاع عمودى بالشتك كردن \\
\hline 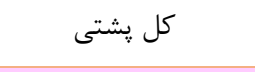 & $r \cdot / V r$ & $\Delta$ & طول گودى تردن & an & طول بالشتك كردن \\
\hline كل رشتى & $\varepsilon / 4 \varepsilon$ & 90 & عمق گَودى گردن & ao & عمق بالشتك كردن \\
\hline كل عشتى & $10 / 9 F$ & $\Delta$ & ارتفاع عمودى گَودى كمر & ap & ارتفاع عمودى بالشتك كمر \\
\hline 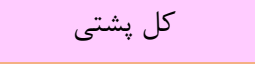 & 1919 & $\Delta$ & طول گودى كمر & aq & طول بالشتك كمر \\
\hline كل رشتى & $r / 14$ & 90 & عمق گودى كمر & ar & عمق بالشتك كمر \\
\hline
\end{tabular}




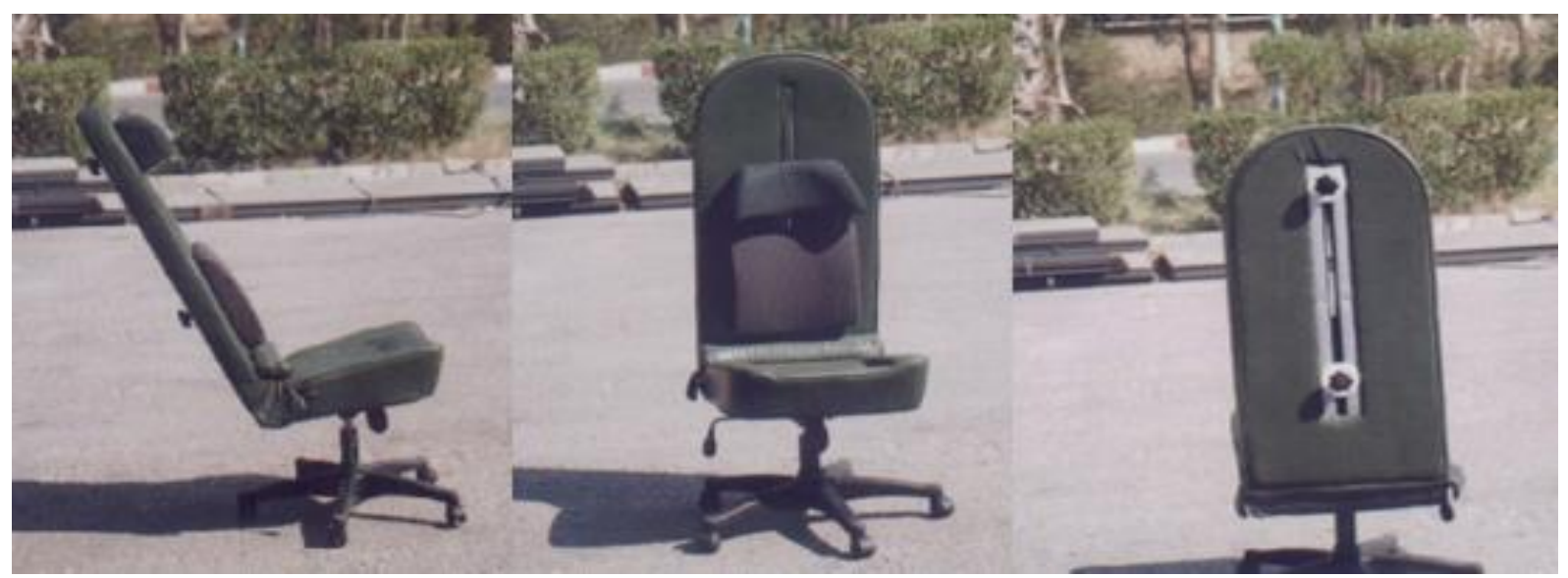

شكل r. صندلى ارَّونومى ساختهشده، از نماهاى مختلف

خواهد داشت [VIV، IV]. قابليت انعطاف سطح نشستن

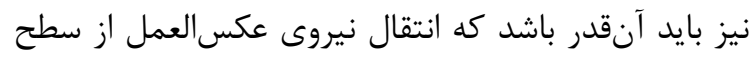

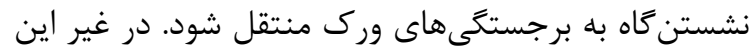

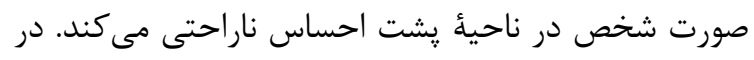
اين مطالعه، قابليت انعطاف سطح نشستن

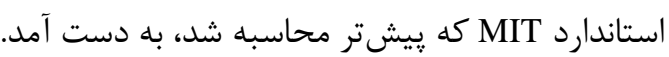

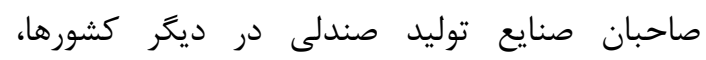

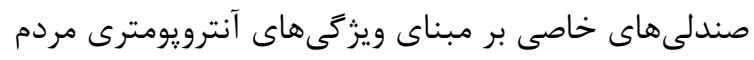

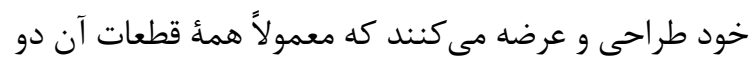

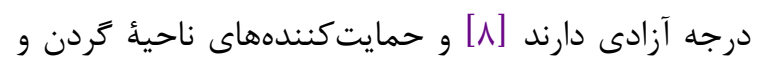

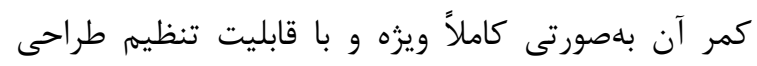

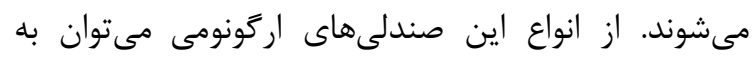
كantonic ،Conventio ،Credo ،Signet

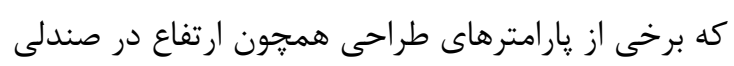
Scio

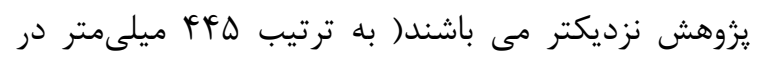

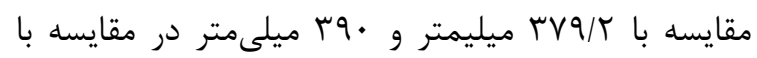
FlN/1

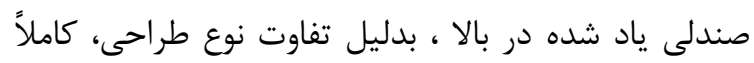
متفاوت مى باشند.

تفاوت مشخصات آنترويومترى نزادهاى مختلف انسانى

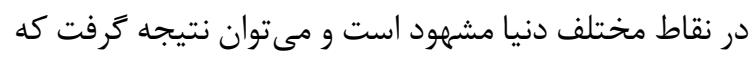
در هر منطقهاى بهتر است طراحى و ساخت انواع صندلى هنا،

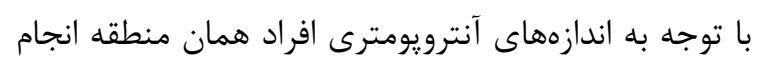
شود.

\section{بحث و نتيجه تَيرى}

نشستن را انسانها هر روز بارها و بارها تجربه مى كنند.

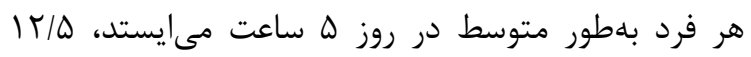

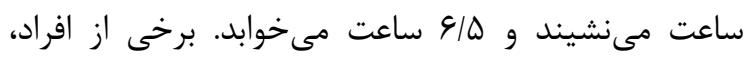

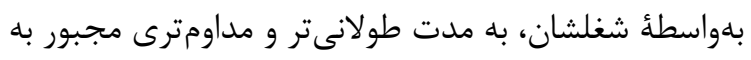

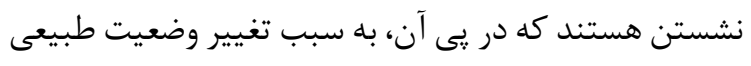

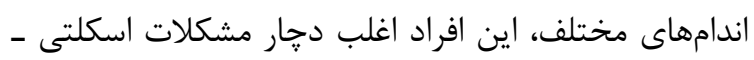

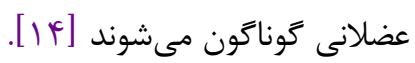

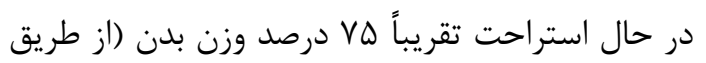

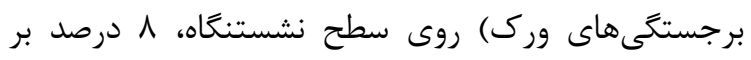

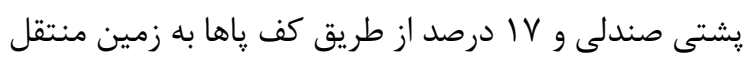

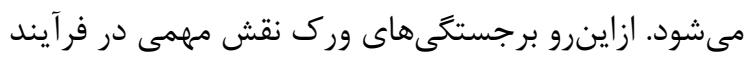

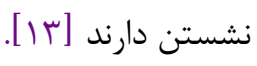

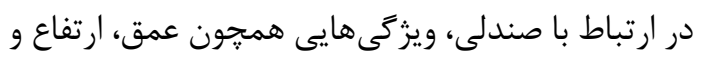

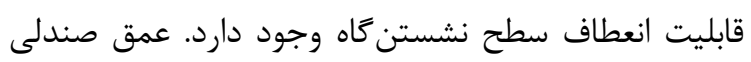

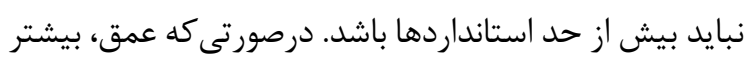

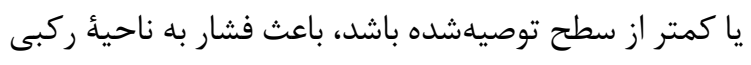

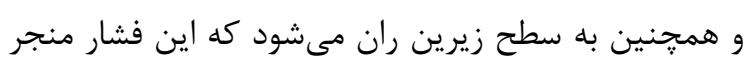

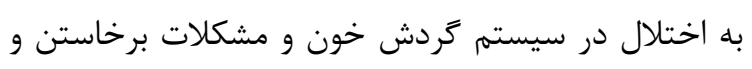

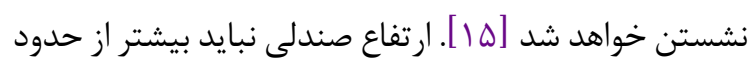

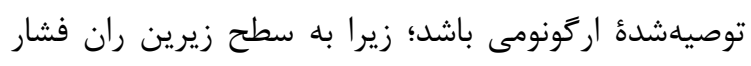

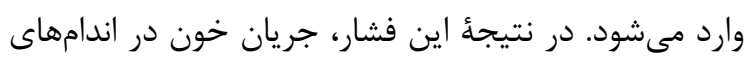

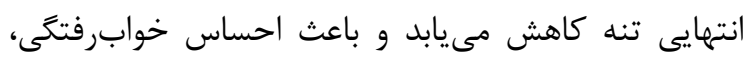

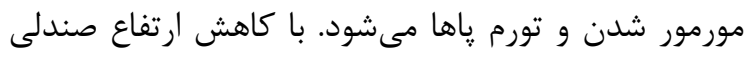

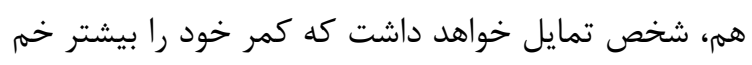

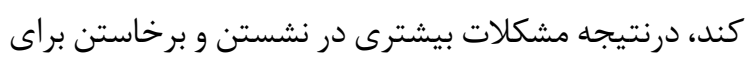
او ييش خواهد آمد و به فضاى خالى بيشترى براى ياها نياز 


$$
\text { تعارض منافع }
$$

\section{References}

1. http://salamattv.irib.ir/archivemaghalat/assetpubl isher/D1b2tEeyX31u/content/id/5696226

2. Anderson GB, Ortengren $\mathrm{T}$, Nachemson A, Elfstorm G. Lumbar disk pressure and myo electric back muscle activity during sitting. Scand J Rehabil Med. 1974;6:101-21.

3. Masoudi. MA. Mohandesi anthropometry. Entesharat Daneshgah olum. Pezeshki. Mazandaran, 1375

4. Sanders MS, McCormic EJ, Human Factors in Engineering and Design (Ergonomic) seven editions. 1999.

5. Bendix T. Seated trunk posture at various seat inclinations, seat heights, and table heights. Human factors. 1984;26(6):695-703. https://doi.org/10.1177/001872088402600609

6. Korean Standard Association. Basic human body measurements for technological design-Part 1: Body measurement definitions and landmarks (KS A ISO 7250-1). Seoul: Korean Industrial Standards. 2008.

7. Panagiotopoulou G, Christoulas K, Papanckolaou A, Mandroukas K. Classroom furniture dimensions and anthropometric measures in primary school. Appl Ergon. 2004 Mar;35(2):121-8. $\quad$ https://doi.org/10.1016 /j.apergo.2003.11.002 PMID:15105073

8. Looze MP, deKuijt-Evers LFM, Dieen J H van, Sitting comfort and discomfort and the relationships with objective measures Ergonomic (2003). 46:985-998.

9. Castellucci HI, Arezes PM, Molenbroek JF. Analysis of the most relevant anthropometric dimensions for school furniture selection based on a study with students from one Chilean region. Appl Ergon. 2015;46 Pt A:201-11. https://doi.org/10.1016/j.apergo.2014.08.005. PMID: 25151312.

$$
\begin{aligned}
& \text { تقد ير و تشكر } \\
& \text { از كليه همكارانى كه در انجام اين يزوهش ما را يارى }
\end{aligned}
$$

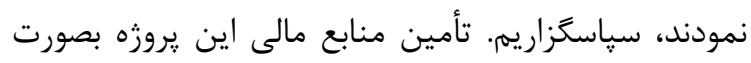

$$
\begin{aligned}
& \text { شخصى گزارش گرديده است. }
\end{aligned}
$$

10. Gouvali MK, Boudolos K. Match between school furnitudimensions and children's anthropometry. Appl Ergon. 2006;37(6):765-73. https://doi.org/10.1016 /j.apergo.2005.11. 009 PMID:16442494

11. Wilke HJ, Neef P, Caimi M, Hoogland T, Claes LE. New in vivo measurements of pressures in the intervertebral disc in daily life. Spine. 1999;24(8):755-62.

https://doi.org/10.1097/00007632-19990415000005 PMID:10222525

12. Pheasant S. Body Space. $2^{\text {nd }} e d$. London: Taylor and Francis; 2003.

13. Different N, Tilley AR, Harman D. Human scale. The MIT Press; 1981.

14. Milanese S, Grimmer K. School furniture and the user population: an anthropometric perspective. Ergonomics. 2004;47(4):416-26. https://doi.org/10.1080/0014013032000157841. PMID: 14680998.

15. Mououdi MA. [Comfort and design]. Iran: Fadakbook; 2015. https://www.fadakbook.ir/ product/1040/

16. Mououdi MA., The determination of static anthropometry characteristics for designing and evaluating the comfort of saddle chair, Iran Occupational Health, 2013.9 (4),24-29.

17. Vink P, Editor. Comfort and design: principles and good practice. CRC press; 2004 Nov 29. 